\title{
Anti-diabetic effects of lemon balm (Melissa officinalis) essential oil on glucose- and lipid-regulating enzymes in type 2 diabetic mice
}

\author{
Mi Ja Chung ${ }^{1,2}$, Sung-Yun Cho ${ }^{1}$, Muhammad Javidul Haque Bhuiyan ${ }^{1}$, Kyoung Heon Kim ${ }^{1}$ \\ and Sung-Joon Lee ${ }^{1 *}$ \\ ${ }^{1}$ Division of Food Bioscience and Technology, College of Life Sciences and Biotechnology, Korea University, Seoul 136-713, \\ Korea \\ ${ }^{2}$ The Nutraceutical Bio Brain Korea 21 Project Group, Kangwon National University, Chuncheon 200-701, Korea
}

(Received 4 August 2009 - Revised 10 March 2010 - Accepted 1 April 2010 - First published online 21 May 2010)

The antioxidant activity of lemon balm (Melissa officinalis) essential oil (LBEO) on 2,2-diphenyl-1-picrylhydrazyl (DPPH) radicals and its hypoglycaemic effect in $d b / d b$ mice were investigated. LBEO scavenged $97 \%$ of DPPH radicals at a 270-fold dilution. Mice administered LBEO $(0.015 \mathrm{mg} / \mathrm{d})$ for 6 weeks showed significantly reduced blood glucose $(65 \% ; P<0.05)$ and TAG concentrations, improved glucose tolerance, as assessed by an oral glucose tolerance test, and significantly higher serum insulin levels, compared with the control group. The hypoglycaemic mechanism of LBEO was further explored via gene and protein expression analyses using RT-PCR and Western blotting, respectively. Among all glucose metabolism-related genes studied, hepatic glucokinase and GLUT4, as well as adipocyte GLUT4, PPAR- $\gamma$, PPAR- $\alpha$ and SREBP-1c expression, were significantly up-regulated, whereas glucose-6-phosphatase and phosphoenolpyruvate carboxykinase expression was down-regulated in the livers of the LBEO group. The results further suggest that LBEO administered at low concentrations is an efficient hypoglycaemic agent, probably due to enhanced glucose uptake and metabolism in the liver and adipose tissue and the inhibition of gluconeogenesis in the liver.

Lemon balm (Melissa officinalis): Hyperglycaemic effects: Glucokinase: GLUT4: Sterol regulatory element-binding protein-1c

Diabetes mellitus is a major public health problem that affects approximately $5 \%$ of the world population ${ }^{(1)}$. Type 2 diabetes is the most common form, accounting for more than $90 \%$ of patients, and is characterised by chronic hyperglycaemia resulting from abnormalities in glucose metabolism and insulin secretion and activity.

Many recent studies on the treatment of type 2 diabetes have focused on the potential use of plant constituents with hypoglycaemic and hypolipidaemic effects. Consequently, there has been a growing interest in herbal essential oils, due to their antioxidative and hypolipidaemic activities ${ }^{(2-5)}$. Several plant constituents have been implicated in insulin signalling pathways modulating glucose transport and glucose metabolism-related enzyme activation, and PPAR activation, all of which play roles in diabetes ${ }^{(6,7)}$. In particular, glucokinase (GCK) gene transcription is stimulated by insulin and increased GCK activity enhances glucose utilisation and uptake in the liver. There have been efforts over recent years to discover and develop GCK activators as a novel therapy for type 2 diabetes ${ }^{(8)}$. Glucose-6-phosphatase (G6Pase) is a key enzyme controlling hepatic gluconeogenesis and glucose output in liver ${ }^{(9,10)}$ and is normally suppressed by insulin $^{(11)}$. Reduced activity of two key gluconeogenic enzymes, phosphoenolpyruvate carboxykinase (PEPCK) and G6Pase, decreases hepatic glucose production ${ }^{(9,10)}$.

In adipose and muscle tissues, insulin stimulates glucose uptake by rapidly recruiting GLUT4 from an intracellular compartment to the plasma membrane ${ }^{(12)}$. PPAR control the expression of many genes involved in glucose and lipid metabolism. In a previous study, a single molecule was found to act as a dual agonist for both PPAR- $\alpha$ and PPAR- $\gamma$, producing simultaneous hypolipidaemic and hypoglycaemic effects, respectively ${ }^{(13)}$. Sterol regulatory element-binding protein (SREBP)-1c is primarily involved in the regulation of fatty acid biosynthesis ${ }^{(14)}$.

In addition to the gene expression changes in glucose metabolism and insulin signalling pathway, oxidative stress plays critical roles in insulin signalling and the aetiology of diabetic complications such as diabetic retinopathy, renal failure and atherosclerosis. Thus, appropriate intake of antioxidative nutrients is beneficial to prevent or ameliorate diabetic symptoms or the development of its complications.

Lemon balm (Melissa officinalis) is a well-known medicinal plant species used in perfumes, cosmetics, tea and food products in many countries, and it has been cited as a mild sedative, a spasmolytic and an antibacterial agent ${ }^{(15)}$. Lemon balm

Abbreviations: DPPH, 2,2-diphenyl-1-picrylhydrazyl; GCK, glucokinase; G6Pase, glucose-6-phosphatase; LBEO, lemon balm essential oil; PEPCK,

phosphoenolpyruvate carboxykinase; SREBP, sterol regulatory element-binding protein.

* Corresponding author: Dr Sung-Joon Lee, fax +82 2925 1970, email junelee@korea.ac.kr 
leaves contain many phytochemicals, including polyphenolic compounds, such as rosmaric acid ${ }^{(16)}$, trimeric compounds ${ }^{(17)}$ and some flavonoids ${ }^{(18)}$. Lemon balm tea contains $10 \mathrm{mg} / \mathrm{l}$ of essential oils and abundant citral ${ }^{(19)}$. Herbal essential oils generally contain a variety of volatile compounds, which may have medicinal properties, including hypolipidaemic and hypoglycaemic effects ${ }^{(2,4,5,14)}$. Some herbal essential oils also possess strong antioxidant activity due to their high contents of tocopherols and phenolic compounds ${ }^{(2,14,20-22)}$.

Although several reports have been published on herbal essential oils, there is no reported information, to our knowledge, regarding the molecular events involved in the glucose-regulating function of this oil, nor has there been any reported study on the hypoglycaemic effect of LBEO in relation to glucose metabolism in a type 2 diabetes model. Accordingly, we analysed the composition of LBEO and assessed its antioxidant effects. We then evaluated the glucose-lowering capacity of LBEO in a model of type 2 diabetes. To further understand the mechanism(s) involved in the beneficial effect(s) of LBEO in diabetes, the gene and protein expression profiles of regulatory enzymes involved in hepatic and adipocyte glucose uptake and hepatic gluconeogenesis were investigated. Furthermore, the influence of LBEO on PPAR- $\gamma$, PPAR- $\alpha$ and SREBP-1c was examined in the liver and adipose tissue of type 2 diabetic mice.

\section{Materials and methods}

\section{Chemicals}

An enhanced chemiluminescence (ECL) plus detection system was obtained from GE Healthcare Life Sciences (Piscataway, NJ, USA). Anti-rabbit IgG and heavy and light (H\&L) chain-specific peroxidase conjugate were purchased from Calbiochem (Darmstadt, Germany). Rabbit anti-mouse PPAR- $\gamma$, rabbit anti-mouse GCK, mouse monoclonal anti- $\alpha$-tubulin, and goat anti-mouse IgG-horseradish peroxidase were purchased from Santa Cruz Biotechnology, Inc. (Santa Cruz, CA, USA), and rabbit anti-mouse GLUT4 was purchased from AbD Serotec (Oxford, UK). PowerScript RT was obtained from Clontech Laboratories (Palo Alto, CA, USA). The oligo $(\mathrm{dT})_{15}$ primer, random hexamers and GoTaq ${ }^{\circledR}$ Green Master Mix PCR kit were purchased from Promega (Madison, WI, USA). A mouse insulin ELISA kit was purchased from Shibayagi, Co., Ltd (Gunma, Japan). All other reagents used were purchased from Sigma Chemical (St Louis, MO, USA).

\section{Preparation of lemon balm essential oil}

Lemon balm essential oil (LBEO) was prepared from lemon balm leaves harvested from the Arboretum of Korea University (Seoul, Korea) in June 2005. The leaves were stored in a plastic bag at $-70^{\circ} \mathrm{C}$ before analysis. A $20 \mathrm{~g}$ portion of leaves was ground using a commercial blender, followed by steam distillation and extraction with $500 \mathrm{ml}$ distilled water and $30 \mathrm{ml}$ diethyl ether for $2 \mathrm{~h}$ at atmospheric pressure. The extract was dried over anhydrous $\mathrm{Na}_{2} \mathrm{SO}_{4}$ at atmospheric pressure and concentrated to $300 \mu \mathrm{l}$ using a gentle stream of $\mathrm{N}_{2}$ gas. Extractions were performed in triplicate.

\section{Analysis of lemon balm essential oil by GC-MS}

GC-MS analysis was conducted using a GC system (Agilent $6890 \mathrm{~N}$; Agilent Technologies, Palo Alto, CA, USA) connected to a mass spectrometer (Quattro GC/MS/MS; Micromass, Manchester, UK). The GC was equipped with a capillary column $(50 \mathrm{~m}$ length $\times 0.25 \mathrm{~mm}$ diameter $\times 0.2 \mu \mathrm{m}$ film thickness; AT-1701; Alltech, Lancaster, PA, USA). A $1 \mu \mathrm{l}$ sample of the extract was injected (splitless mode) into each column. The oven temperature was programmed to increase from $40^{\circ} \mathrm{C}$, with an initial holding time of $2 \mathrm{~min}$, to $120^{\circ} \mathrm{C}$ at $3^{\circ} \mathrm{C} / \mathrm{min}$, and then finally to $200^{\circ} \mathrm{C}$ at $5^{\circ} \mathrm{C} / \mathrm{min}$. The flow rate of the $\mathrm{He}$ carrier gas was $1.0 \mathrm{ml} / \mathrm{min}$. The injector and detector temperatures were held at 280 and $240^{\circ} \mathrm{C}$, respectively. Using perfluorotributyl amine, the parameters of the mass spectrometer were optimised for the best resolutions at $69 \mathrm{~m} / \mathrm{z}, 219 \mathrm{~m} / \mathrm{z}, 502 \mathrm{~m} / \mathrm{z}$ and $614 \mathrm{~m} / \mathrm{z}$. Mass measurement was conducted using an electron ionisation (EI) positive ion source at $240^{\circ} \mathrm{C}$ in the SCAN mode in the mass range of $33-350 \mathrm{~m} / \mathrm{z}$.

\section{Identification and quantification}

Total ion chromatograms of the samples were analysed using MassLynx 4.0 software (MassLynx 4.0 SCN 474; Micromass), and the compounds were positively identified using the Wiley mass spectral database (2002; John Wiley \& Sons, New York, NY, USA).

\section{Antioxidant activity test}

The effect of LBEO on 2,2-diphenyl-1-picrylhydrazyl (DPPH) radical-scavenging activity was estimated according to the method of Singh \& Rajini ${ }^{(23)}$, with minor modifications. Samples of $900 \mu \mathrm{l}$ at various concentrations (10-fold to 47829690 -fold dilutions) were mixed with $300 \mu$ l of DPPH solution $\left(1.5 \times 10^{-4} \mathrm{M}\right)$ and then the tube was mixed by vortexing. The mixture was incubated at $37^{\circ} \mathrm{C}$ for $30 \mathrm{~min}$ and the decrease in absorbance at $532 \mathrm{~nm}$ was measured. The antioxidant was able to reduce the stable radical DPPH to the yellow-coloured diphenylpicrylhydrazine product. The percentage inhibition of DPPH was calculated using the following equation:

$$
\begin{aligned}
& \text { Radical-scavenging activity }(\%) \\
& =\left(\left(\mathrm{A}_{\text {sample }(517 \mathrm{~nm})} / \mathrm{A}_{\text {control }(517 \mathrm{~nm})}\right)\right) \times 100,
\end{aligned}
$$

where $A_{\text {sample }(517 \mathrm{~nm})}$ is the absorbance of the sample and $A_{\text {control }(517 \mathrm{~nm})}$ is the absorbance of the control at $517 \mathrm{~nm}$.

\section{Animals and feeding protocol}

Male C57BL/KsJ- $d b / d b(d b / d b)$ mice were obtained from Orient Bio (Gyeonggi-Do, Korea). Animal rooms were maintained at $21^{\circ} \mathrm{C}$ under humidity-controlled conditions and a $12 \mathrm{~h}$ light $-12 \mathrm{~h}$ dark cycle. At 15 weeks of age, mice were fed normal chow or chow with $M$. officinalis essential oil ( $0.0125 \mathrm{mg} \mathrm{LBEO} / \mathrm{d})$ for 6 weeks. After feeding, the mice were fasted overnight $(16-19 \mathrm{~h})$, and blood samples were collected in purple top tubes containing EDTA once every 3 weeks. Plasma samples were obtained from blood by 
centrifugation (10000 rpm, $10 \mathrm{~min}$ ). Glucose, total cholesterol, TAG and HDL-cholesterol levels were determined by enzymic methods (Asan Pharmaceuticals, Hwasung, South Korea). At the end of 6 weeks, an oral glucose tolerance test was performed and the mice were killed to obtain several organs. Organs were snap-frozen in liquid $\mathrm{N}_{2}$ and stored at $-80^{\circ} \mathrm{C}$ for total RNA and protein extraction. All experimental procedures involving animals were approved by the Korea University Institutional Animal Care and Use Committee.

\section{Oral glucose tolerance tests}

An oral glucose tolerance test was performed after 6 weeks following an overnight fast $(16 \mathrm{~h})$. The mice were administered glucose orally at $0.25 \mathrm{~g} / \mathrm{kg}$ body weight. The blood glucose concentration was determined in tail blood samples taken $0,15,30,60,90$ and $120 \mathrm{~min}$ after glucose administration using a glucometer (MyCare GAM-2200; Green Cross, Yongin, Korea).

\section{Serum insulin levels}

Blood was collected in tubes without heparin or EDTA and centrifuged $(10000 \mathrm{rpm} ; 10 \mathrm{~min})$. The serum insulin level was determined using a mouse insulin ELISA kit (Shibayagi, Co., Ltd, Gunma, Japan); this reagent kit is for the quantification of insulin by a sandwich-technique enzyme immunoassay.

\section{Isolation of total RNA and RT-PCR}

Total RNA was extracted from liver or adipose tissue using a Sigma TRI reagent kit, according to the manufacturer's protocol, and was then dissolved in diethylpyrocarbonate-treated water. For cDNA synthesis, total RNA $(2 \mu \mathrm{g})$ was reverse transcribed using PowerScript RT (Clontech, Mountain View, CA, USA), according to the protocol supplied, using a combination of oligo $(\mathrm{dT})_{15}$ primer and random hexamers. PCR was performed using the GoTaq ${ }^{\circledR}$ Green Master Mix PCR kit (Promega) in a $20 \mu l$ reaction mixture containing $1 \mu l$ of the RT reaction mixture and $0.5 \mu l$ of each primer (forward and reverse, $15 \mu \mathrm{M}$ ). PCR primers were designed using published nucleotide sequences for $\mathrm{GCK}^{(6)}, \mathrm{G} \mathrm{Pase}{ }^{(6)}$, PEPCK $^{(6)}$, GLUT2 $^{(24)}$, PPAR- $\alpha^{(25)}$, PPAR- $\gamma^{(25)}$, GLUT4 $^{(26)}$, SREBP-1c ${ }^{(24,27)}$ and $\beta$-actin ${ }^{(27)}$.

The following in vivo primers were used: for GCK, forward 5'-TTC ACC TTC TCC TTC CCT GTA AGG C-3' and reverse 5'-TAC CAG CTT GAG CAG CAC AAG TCG-3'; for G6Pase, forward 5'-AAG ACT CCC AGG ACT GGT TCA TCC- $3^{\prime}$ and reverse $5^{\prime}$-TAG CAG GTA GAA TCC AAG CGC G-3'; for PEPCK, forward 5'-TGC TGA TCC TGG GCA TAA CTA ACC- $3^{\prime}$ and reverse $5^{\prime}$-TGG GTA CTC CTT CTG GAG ATT $\mathrm{CCC}-3^{\prime}$; for PPAR- $\alpha$, forward $5^{\prime}-\mathrm{CCT} \mathrm{CAG}$ GGT ACC ACT ACG GAG T-3' and reverse $5^{\prime}$-GCC GAA TAG TTC GCC GAA-3'; for PPAR- $\gamma$, forward $5^{\prime}$-TAG GTG TGA TCT TAA CTG TCG-3' and reverse $5^{\prime}$-GCA TGG TGT AGA TGA TCT CA-3'; for GLUT2, forward 5'-GGC TAA TTT CAG GAC TGG TT-3' and reverse 5'-TTT CTT TGC CCT GAC TTC CT-3'; for GLUT4, forward $5^{\prime}$-CCT GCC CGA AAG AGT CTA AAG C-3' and reverse 5'-ACT AAG AGC ACC GAG ACC AAC G-3'; and for SREBP-1c, forward 5'-GGA GCC ATG GAT TGC ACA TT- $3^{\prime}$ and reverse $5^{\prime}$-GGC CCG GGA AGT CAC TGT- $3^{\prime}$. The $\beta$-actin transcript (forward $5^{\prime}$-TGC TGT CCC TGT ATG CCT CT- $3^{\prime}$ and reverse $5^{\prime}$-AGG TCT TTA CGG ATG TCA ACG-3') was used as an internal control.

PCR using the GCK primer was performed with an initial cycle of $4 \mathrm{~min}$ at $94^{\circ} \mathrm{C}$, followed by twenty-two cycles of $30 \mathrm{~s}$ at $94^{\circ} \mathrm{C}, 30 \mathrm{~s}$ at $57^{\circ} \mathrm{C}$, and $30 \mathrm{~s}$ at $72^{\circ} \mathrm{C}$, and a final extension for $5 \mathrm{~min}$ at $72^{\circ} \mathrm{C}$. PCR using the G6Pase, PEPCK, PPAR- $\alpha$, PPAR- $\gamma$, GLUT2, GLUT4, SREBP-1c and $\beta$-actin primers was performed similarly, with the exception of the annealing temperature (G6Pase, $57^{\circ} \mathrm{C}$; PEPCK, $57^{\circ} \mathrm{C}$; PPAR- $\alpha, 50^{\circ} \mathrm{C}$; PPAR- $\gamma, 52^{\circ} \mathrm{C}$; GLUT2, $47^{\circ} \mathrm{C}$; GLUT4, $54^{\circ} \mathrm{C}$; SREBP- $1 \mathrm{c}, 54^{\circ} \mathrm{C} ; \beta$-actin, $50^{\circ} \mathrm{C}$ ) and the number of cycles (G6Pase, twenty cycles; PEPCK, nineteen cycles; PPAR- $\alpha$, twenty-three cycles; PPAR- $\gamma$, twentysix cycles; GLUT2, twenty-eight cycles; GLUT4, twenty-six cycles; SREBP-1c, twenty-five cycles; $\beta$-actin, twenty-two cycles). The $\beta$-actin transcripts were used as internal controls.

\section{Western blotting}

Liver and adipose tissue were homogenised in a buffer containing $10 \mathrm{mM}$-2-amino-2-hydroxymethyl-propane-1,3diol- $\mathrm{HCl}$ ( $\mathrm{pH} 7.4$ ), 0.1 M-EDTA, $10 \mathrm{~mm}-\mathrm{NaCl}, 0.5 \%$ Triton $\mathrm{X}-100$, and one protease inhibitor cocktail tablet, at $4^{\circ} \mathrm{C}$. The homogenates were then centrifuged $(14000 \mathrm{rpm}, 10 \mathrm{~min}$, $4^{\circ} \mathrm{C}$ ). The protein concentration was determined using a BioRad protein kit with bovine serum albumin (Sigma, St Louis, MO, USA) as the standard. Equal amounts of protein were boiled in sample buffer (with $5 \% \beta$-mercaptoethanol) for $5 \mathrm{~min}$. The proteins were separated via $10 \%$ SDS-PAGE and transferred to a nitrocellulose membrane $(0.45 \mu \mathrm{m}$ Protran Nitrocellulose Transfer Membrane; Schleicher \& Schuell BioScience, Dassel, Germany). The membranes were then incubated with an anti-mouse GCK (rabbit polyclonal $\mathrm{IgG}$ ), anti-mouse PPAR- $\gamma$ (rabbit polyclonal IgG), or anti-mouse GLUT4 (rabbit polyclonal IgG) antibody, and monoclonal anti- $\alpha$-tubulin (mouse Ig) antibody (1/700). After washing several times with PBS-0.1\% Tween 20, the membrane was incubated with $1 / 2500$ anti-rabbit $\operatorname{IgG}$ or anti-mouse IgG with $\mathrm{H} \& \mathrm{~L}$ chain-specific (goat) peroxidase-conjugated secondary antibody. Immunoreactive bands were detected using an ECL kit (GE Healthcare Life Sciences, Piscataway, NJ, USA), according to the manufacturer's protocol, and exposed to high-performance chemiluminescence film for $10 \mathrm{~s}$. Protein immunoblots were scanned with a 690 Bio-Rad densitometer using the Multi-Analyst program (Bio-Rad, Hercules, CA, USA) and quantified using SigmaGel software (Jandel Scientific, San Rafael, CA, USA).

\section{Statistical analyses}

Data from three independent experiments were expressed as mean values and standard deviations. One-way ANOVA followed by Tukey's test was used to compare the results from different treatments. Student's $t$ test was used for comparisons between groups. Data were deemed to be statistically significantly different at $P<0.05$. 


\section{Results}

\section{Composition of lemon balm essential oil}

There were forty constituents identified in the essential oil of the leaves of lemon balm (M. officinalis) that accounted for $99.7 \%$ of the total oil components, as revealed by the GC-MS analysis (Table 1). Monoterpene hydrocarbons, including $\beta$-pinene $(0.3 \%)$, oxygenated monoterpenes, including 2,3-dehydro-1,8-cineole $(0 \cdot 1 \%)$, linalool $(0 \cdot 8 \%)$, myrtenol $(0.1 \%),(Z)$-carveol $(0.1 \%)$, geranial $(65.4 \%)$, neral $(24.7 \%)$, geranylacetate $(7.4 \%)$ and sesquiterpene hydrocarbons, including caryophyllene $(0.8 \%)$ and farnesene $(0.1 \%)$, were found to be the major volatile compounds.

Table 1. Composition of the essential oil of lemon balm (Melissa officinalis)

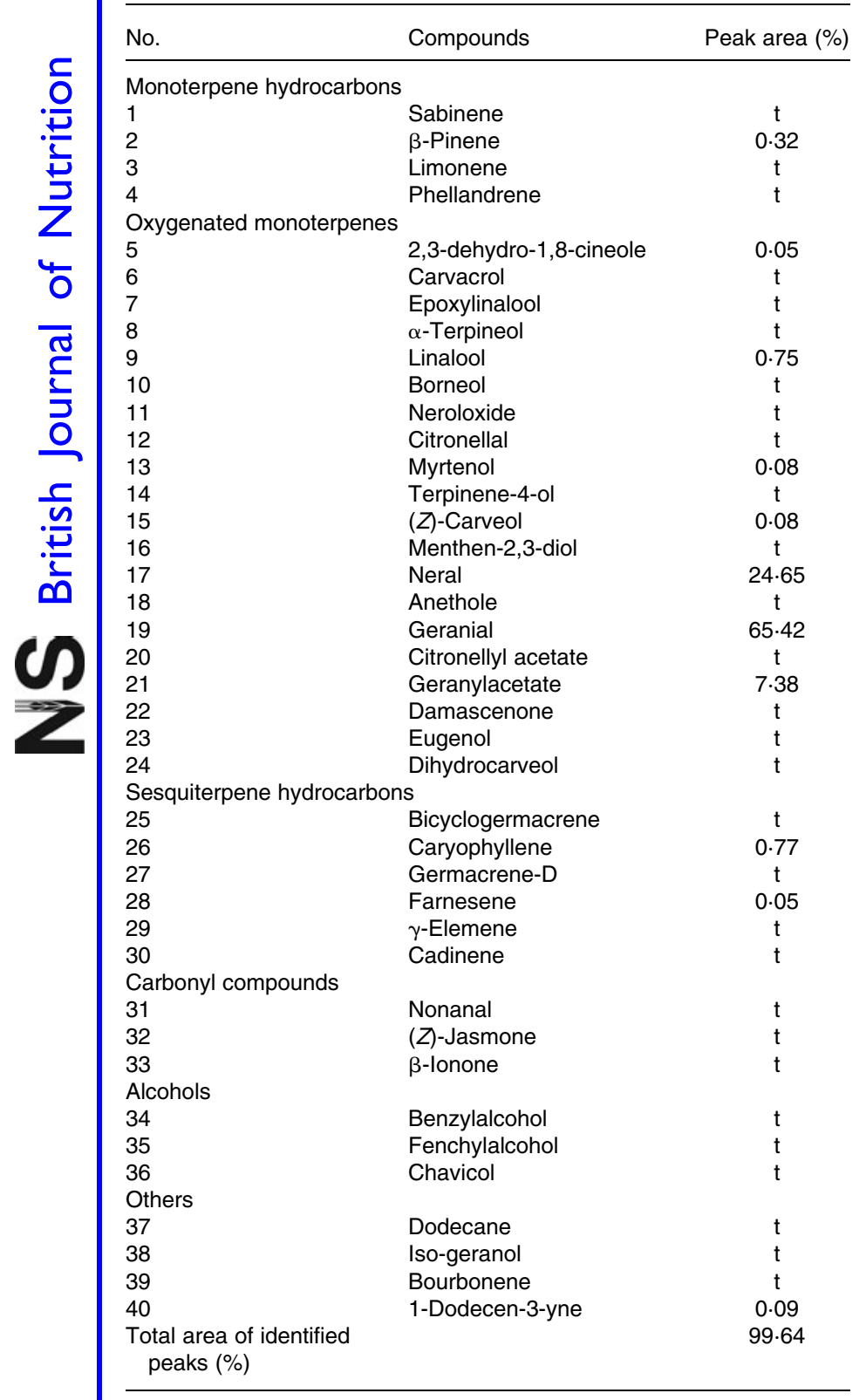

$\mathrm{t}$, Trace amount (less than $0.05 \%$ of total peak area).

\section{Antioxidant activity of lemon balm essential oil}

The effect of LBEO on DPPH radical-scavenging activity was tested (Fig. 1). DPPH reactivity is commonly used to determine the free radical-scavenging ability of antioxidative phytochemicals. In Fig. 1, the DPPH radical-scavenging activities of LBEO at various concentrations are compared with those of ascorbic acid and vitamin E. The DPPH radical-scavenging activity of LBEO increased significantly from the 196830fold dilution to the 270 -fold dilution in a dose-dependent manner. A similar effect was found with ascorbic acid and vitamin $\mathrm{E}$ at high concentrations (270-fold to 10-fold dilutions), although these two antioxidants showed high antioxidant activities even at much higher dilutions.

Effects of lemon balm essential oil on plasma glucose levels, oral glucose tolerance test, and serum insulin concentrations

The baseline values (week 0) for plasma blood glucose were similar between groups, although levels in the LBEO group decreased significantly after 3 and 6 weeks of LBEO treatment, compared with the control group, and blood glucose levels decreased by up to $64.6 \%$ (Fig. 2(a)). The administration of LBEO also improved glucose tolerance in $d b / d b$ mice (Fig. 2(b)). Blood glucose levels at 0,15 and $120 \mathrm{~min}$ after glucose loading were significantly $(P<0.05)$ lower in the LBEO group $v$. the control group (Fig. 2(b)). In contrast, serum insulin levels showed a significant increase $(P<0.05)$ in the LBEO group, compared with the control group, at 3 and 6 weeks (Fig. 2(c)). Body weight (28.3 (SD 0.6) v. 28.2 (SD 0.5) g in control and LBEO mice, respectively) and total fat content (2.6 (SD $0 \cdot 1)$ v. $2 \cdot 5(\mathrm{SD} 0 \cdot 1) \mathrm{g}$ in control and LBEO, respectively) were not changed after 6 weeks of LBEO feeding.

\section{Effects of lemon balm essential oil on plasma lipids levels}

Plasma TAG concentrations were significantly lower $(P<0 \cdot 05)$ in the LBEO group than in the control group

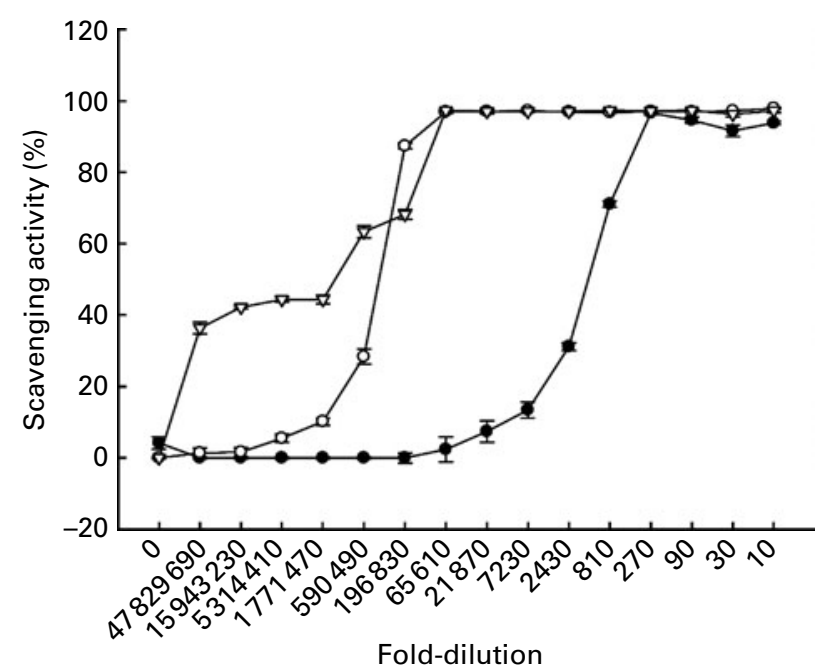

Fig. 1. Effects of lemon balm (Melissa officinalis) essential oil (-0-) compared with ascorbic acid (-O-) and vitamin $E(-\nabla-)$ on 2,2-diphenyl-1picrylhydrazyl radical-scavenging activity. Values are means $(n 4)$, with standard deviations represented by vertical bars. 

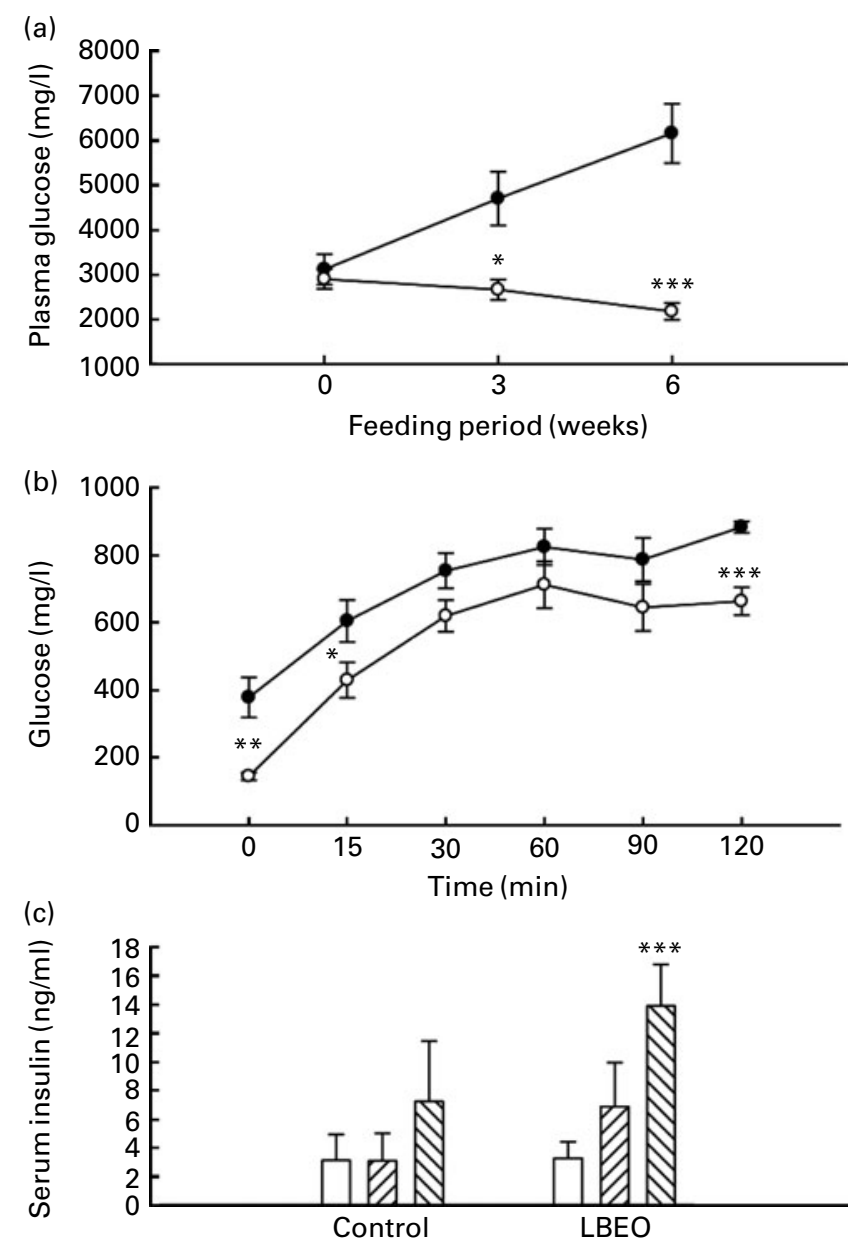

Fig. 2. Effects of lemon balm (Melissa officinalis) essential oil (LBEO; $-\bigcirc-$ ) compared with control (-๑) on (a) plasma glucose, (b) glucose tolerance and (c) serum insulin levels at 0 weeks $(\square), 3$ weeks $(\mathbb{C})$ and 6 weeks $(\mathbb{Q})$. Values are means for six mice, with standard deviations represented by vertical bars. Mean value was significantly different from that of the control group: ${ }^{\star} P<0.05,{ }^{* \star} P<0.01,{ }^{\star \star *} P<0.001$.

(a 29.2\% decrease; Fig. 3). However, no significant difference in plasma total cholesterol or HDL-cholesterol was observed compared with the control group at 3 or 6 weeks (Fig. 3).
Gene and protein expression of hepatic glucose-regulating enzymes

A number of key hepatic glycolytic and gluconeogenic genes were assayed by RT-PCR and Western blotting. The LBEO supplementation resulted in a significant decrease in G6Pase and PEPCK mRNA levels compared with the controls (Fig. 4(a)), whereas the GCK mRNA and protein levels were increased significantly in response to LBEO administration in $d b / d b$ mice compared with controls (Fig. 4(b) and (c)).

Expression of glucose transporters, PPAR- $\gamma$, PPAR- $\alpha$ and sterol regulatory element-binding protein-1c

Changes in GLUT4, GLUT2, PPAR- $\gamma$, PPAR- $\alpha$ and SREBP1c expression were determined. The mRNA expression of hepatic GLUT4 and SREBP-1c and adipocyte GLUT4, PPAR- $\gamma$, PPAR- $\alpha$ and SREBP-1c was significantly higher in the LBEO group than in the control group (Fig. 5(a)). Hepatic and adipocyte GLUT4 mRNA levels were 1.5- and 2.6-fold higher, respectively, and their corresponding protein levels were approximately 1.5 - and 1.3 -fold higher, respectively, in the LBEO group (Fig. 5(a) and (b)). Adipocyte PPAR- $\gamma$ protein expression increased significantly in the LBEO-fed group. However, no significant difference was observed in hepatic GLUT2, PPAR- $\gamma$ or PPAR- $\alpha$ mRNA transcription.

\section{Discussion}

In previous studies, we showed that Asian plantain (Plantago asiatica) and wormwood (Artemisia princeps) essential oils had strong antioxidant effects; they also showed hypocholesterolaemic effects through the suppression of 3-hydroxy3-methyl-glutaryl-co-enzyme A reductase expression and the up-regulation of LDL receptor expression, in vitro and in vivo ${ }^{(2,14)}$. This prompted us to examine other herbal essential oils for activities that may be helpful in preventing and treating various diseases. Thus, we assessed the hypoglycaemic effects of LBEO.

The present results showed that the LBEO had strong antioxidant activity and contained large amounts of neral $(24.7 \%)$ and geranial $(65.4 \%)$ volatile oils. In the present study, LBEO administered orally $(0.0125 \mathrm{mg} / \mathrm{d})$ for 6 weeks did not appear to produce any toxicity in $d b / d b$ mice; in fact, the activities of plasma transaminases (aspartate aminotransferase and alanine

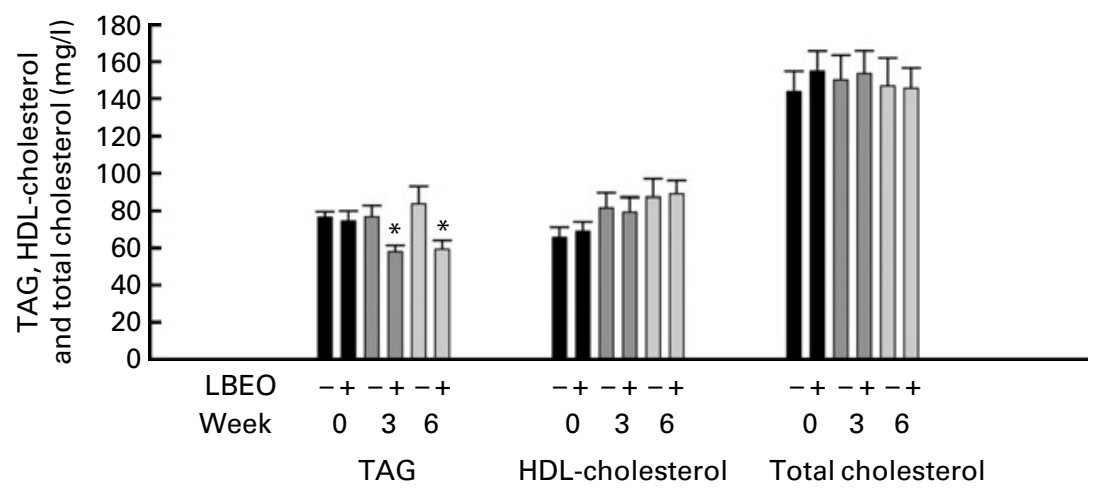

Fig. 3. Effects of lemon balm (Melissa officinalis) essential oil (LBEO) on plasma TAG, HDL-cholesterol and total cholesterol levels. Values are means for six mice, with standard deviations represented by vertical bars. * Mean value was significantly different from that of the control group $(P<0.05)$. 


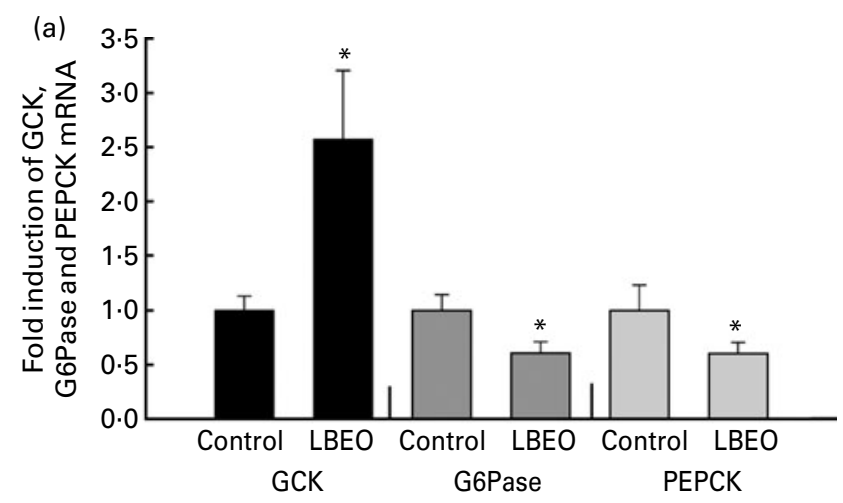

(b)

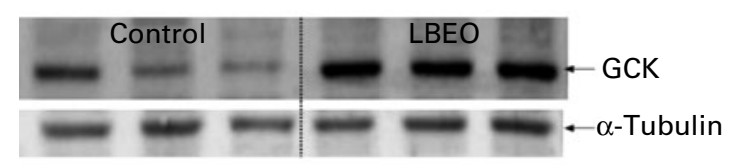

(c)

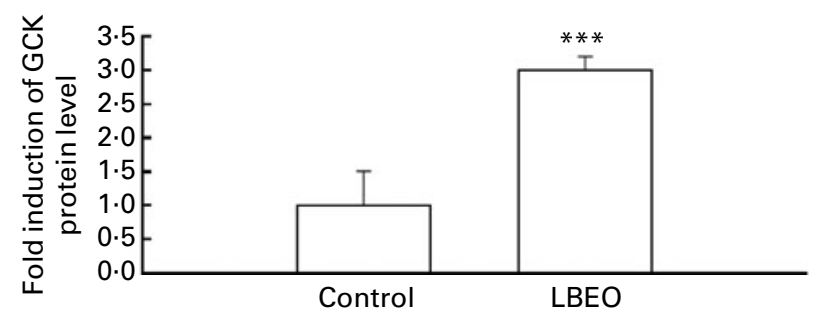

Fig. 4. Effects of lemon balm (Melissa officinalis) essential oil (LBEO) on hepatic glucokinase (GCK), glucose-6-phosphatase (G6Pase), and phosphoenolpyruvate carboxykinase (PEPCK) mRNA transcription (a) and hepatic GCK protein expression ( $b$ and $c$ ). The density of each band on the Western blot (protein) and RT-PCR gel (mRNA) was quantified using SigmaGel software (Jandel Scientific, San Rafael, CA, USA). The mRNA and protein levels in each sample were normalised against the quantity of $18 \mathrm{~s}$ RNA or $\alpha$-tubulin. Values are means for six mice, with standard deviations represented by vertical bars. Mean value was significantly different from that of the control group: ${ }^{*} P<0.05,{ }^{\star \star \star} P<0.001$.

aminotransferase) decreased in response to LBEO supplementation (data not shown), indicating that LBEO did not induce liver damage at the dose used here. To date, twenty chemical components have been isolated from the leaves of lemon balm $^{(19)}$. In the present study, the major aromatic components were neral $(20.4 \%)$ and geranial $(27.8 \%)$; thus, the present results regarding the composition and antioxidant activity of lemon balm leaf essential oil were consistent with previous reports $^{(19,21)}$.

Since oxidative stress and reactive oxygen species could cause diabetes and its complications, appropriate intake of antioxidative nutrients, such as LBEO, may be beneficial to prevent or ameliorate diabetic symptoms or complications. There is evidence that reactive oxygen species in cells act as a double-edged sword in modulating insulin signalling ${ }^{(28,29)}$. Reactive oxygen species are generated in response to insulin and they are somewhat necessary to normal insulin activities, but, on the other hand, recent evidence suggests that reactive oxygen species are negative regulators of insulin signalling, rendering them putative mediators in the development of insulin resistance and obesity. Oxidative stress is also particularly important in the development of various diabetic complications such as diabetic retinopathy, renal failure and atherosclerosis. There are mainly four mechanisms regarding these ${ }^{(30)}$ : first, activation of protein kinase $\mathrm{C}$ isoforms; second, increased hexoamine pathway flux; third, increased polyol pathway flux, which aldose reductase mediates conversion of glucose to sorbitol and excess sorbitol causes oxidative damage and activates stress genes; fourth, increased advanced glycation endproduct formation, which bind to specific cell surface receptors and lead to post-receptor signalling and further generation of reactive oxygen species. Thus, the antioxidant effect of LBEO will help to prevent diabetes and its complications.

In the present study, LBEO supplementation significantly reduced plasma glucose levels compared with the control group, and augmented glucose tolerance in a type 2 diabetic model. Serum insulin concentrations were increased significantly in the LBEO group compared with the control group. These results are consistent with those of previous reports describing the hypoglycaemic effects of citrus flavonoids and Du-zhong (Eucommia ulmoides Oliver) leaf water extract, and increased plasma insulin levels in response to treatment with Du-Zhong leaf water extract ${ }^{(6,7)}$

LBEO treatment decreased glucose concentrations by stimulating GCK activity and inhibiting G6Pase activity in the livers of $d b / d b$ mice. Hepatic GCK activity was increased significantly, whereas those of G6Pase and PEPCK were decreased significantly in the LBEO group compared with the control group. Key liver genes for carbohydrate and lipid homeostasis are regulated by insulin and glucose ${ }^{(31,32)}$. GCK catalyses the conversion of glucose into glucose6-phosphate in the liver, thus playing a key role in the control of glucose homeostasis by supplying glucose-6-phosphate for glycogen storage, glycolysis or the pentose phosphate pathway. For these reasons, the GCK gene has been considered as a potential target for the pharmacological treatment of type 2 diabetes in recent years ${ }^{(33)}$. A major effect of insulin in the liver is the induction of GCK gene expression, which is a key step in the subsequent activation of hepatic glycolytic and lipogenic gene expression by glucose ${ }^{(34-36)}$. Many studies have also indicated that G6Pase and PEPCK activities are higher in type 2 diabetes mellitus ${ }^{(7,37,38)}$, whereas supplementation with several plant constituents significantly lowered G6Pase and PEPCK activities ${ }^{(6,7)}$. Additionally, an abnormal increase in hepatic glucose production is a major symptom of diabetes and contributes to fasting hyperglycaemia ${ }^{(39)}$, apparently as a consequence of increased G6Pase activity and decreased GCK activity. Among glucose-regulating genes, the enhanced expression of the hepatic PEPCK gene has been identified in most forms of diabetes, and contributes to increased hepatic glucose output ${ }^{(40)}$. Accordingly, LBEO treatment appears to improve glucose metabolism through an increase in GCK activity and a decrease in gluconeogenic enzyme activity (i.e. G6Pase and PEPCK).

SREBP-1c has been proposed as a major mediator of insulin action on GCK transcription ${ }^{(41,42)}$. In a previous study, GCK gene transcription was regulated by SREBP-1c and insulin in cultured rat hepatocytes, and SREBP-1c activation up-regulated insulin-sensitive GLUT4 expression in liver, muscle and adipocytes ${ }^{(43)}$. Insulin binding to the insulin receptor regulates glucose uptake into cells via GLUT4, indicating a major role for GLUT4 in glucose uptake and metabolism.

PPAR- $\gamma$ activation restores the glucose-sensing ability of $\beta$-cells through the increased expression of GLUT2 and 


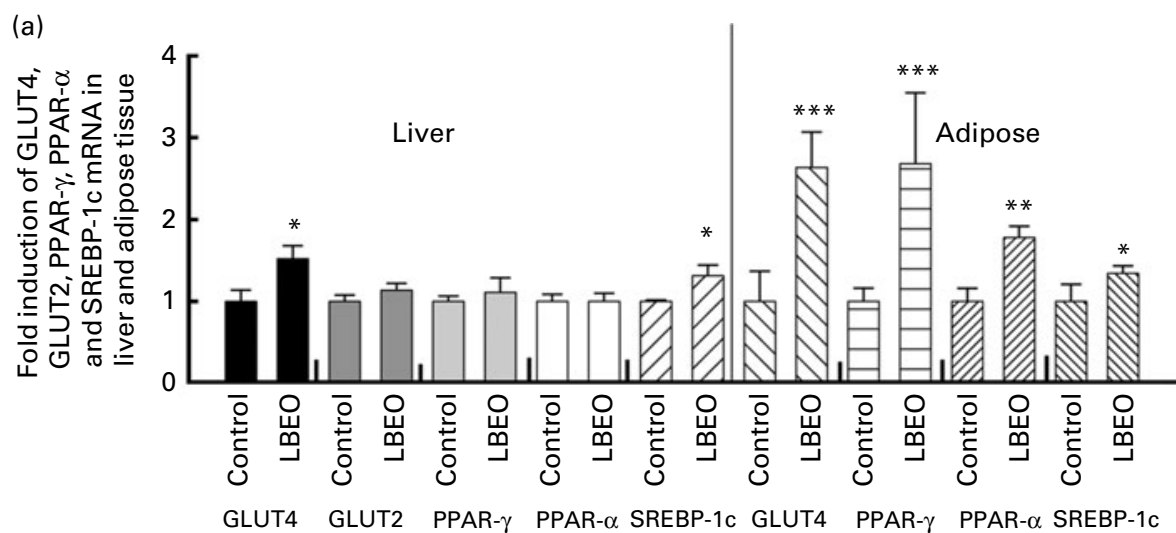

(b)

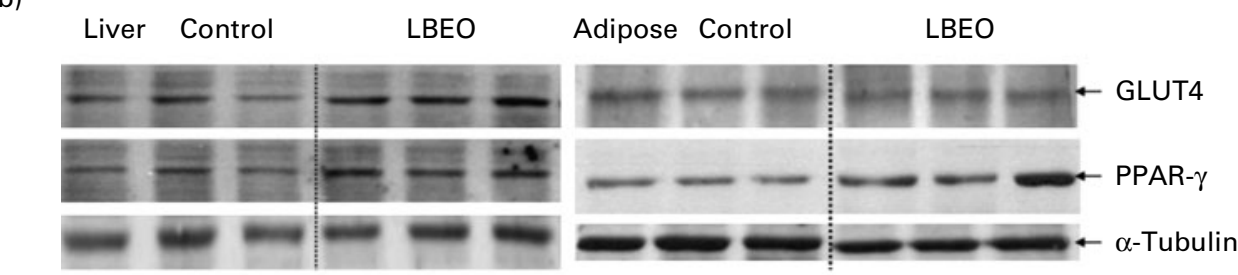

(c)

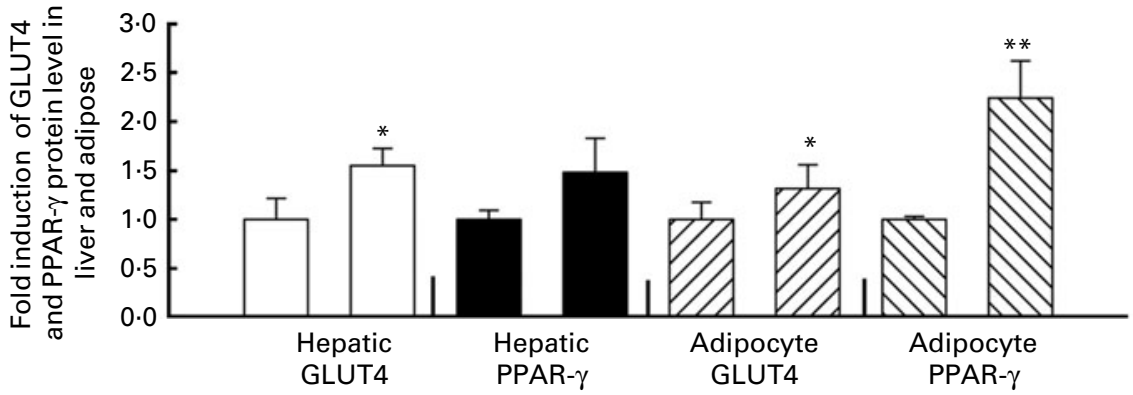

Fig. 5. Effects of lemon balm (Melissa officinalis) essential oil (LBEO) on hepatic GLUT4, GLUT2, PPAR- $\gamma$, PPAR- $\alpha$ and sterol regulatory element-binding protein (SREBP)-1c, and on adipocyte GLUT4, PPAR- $\gamma$, PPAR- $\alpha$ and SREBP-1c mRNA transcription (a), and GLUT4 and PPAR- $\gamma$ protein levels in liver and adipose tissue ( $b$ and $c$ ) of $d b / d b$ mice. The density of each band on the Western blot (protein) and RT-PCR gel (mRNA) was quantified using SigmaGel software (Jandel Scientific, San Rafael, CA, USA). The mRNA and protein levels in each sample were normalised against the quantity of 18s RNA or $\alpha$-tubulin expression. Values are means for six mice, with standard deviations represented by vertical bars. Mean value was significantly different from that of the control group: ${ }^{*} P<0.05$, ${ }^{\star \star} P<0.01,{ }^{* \star *} P<0.001$.

$\mathrm{GCK}^{(44)}$. PPAR- $\gamma$ activation increases the expression and translocation of GLUT1 and GLUT4 to the cell surface, thus increasing glucose uptake in adipocytes and muscle cells ${ }^{(45)}$, and reducing glucose plasma levels.

In the present study, serum insulin levels were significantly higher in LBEO-supplemented $d b / d b$ mice compared with control mice. Insulin-regulated GLUT4 mRNA levels were also significantly higher in the LBEO group than in the control group. However, the molecular mechanism(s) by which insulin regulates GCK gene expression remain(s) controversial.

In the present study, the plasma TAG concentrations were significantly lowered in the LBEO group, which was observed in association with a simultaneous increase in SREBP-1c mRNA transcription and PPAR- $\gamma$ protein expression in the liver and adipose tissue. SREBP-1c promotes the expression of genes involved in fatty acid synthesis. PPAR- $\gamma$ activation induces the expression of genes controlling adipocyte fatty acid metabolism, including those that encode lipoprotein lipase and fatty acid transport proteins, thus leading to lipolysis of plasma TAG, uptake of fatty acids and the storage of TAG in adipocytes.

In conclusion, the present data suggest that LBEO is an anti-hyperglycaemic agent that mediates its effects through the activation of GCK and the inhibition of G6Pase and PEPCK in the liver. Increased GLUT4, SREBP-1c, PPAR- $\gamma$ and PPAR- $\alpha$ expression in the liver and adipose tissue may provide additional anti-diabetic benefits.

\section{Acknowledgements}

The present study was supported by a grant from the BioGreen 21 Program, Rural Development Administration, Republic of Korea (20080401-034-049-009-01-00) and with the support of 'Forest Science \& Technology Projects (project no. S120909L130110)' provided by Korea Forest Service.

M. J. C. was the main researcher in performing animal experiments, lipid and gene expression analyses and also wrote the manuscript. S.-Y. C. assisted in immunoblot 
analysis. M. J. H. B. assisted in data interpretation and manuscript preparation. K. H. K. provided GC/MS analysis data. S.-J. L. was the principal investigator in the project.

There are no conflicts of interest.

\section{References}

1. Taylor SI (1999) Deconstructing type 2 diabetes. Cell 97, 9-12.

2. Chung MJ, Park KW, Kim KH, et al. (2008) Asian plantain (Plantago asiatica) essential oils suppress 3-hydroxy-3-methylglutaryl-co-enzyme A reductase expression in vitro and in vivo and show hypocholesterolaemic properties in mice. $\mathrm{Br} J$ Nutr 99, 67-75.

3. Chung MJ, Sung NJ, Park CS, et al. (2008) Antioxidative and hypocholesterolemic activities of water-soluble puerarin glycosides in HepG2 cells and in C57BL/6J mice. Eur J Pharmacol 578, 159-170.

4. Clegg RJ, Middleton B, Bell GD, et al. (1982) The mechanism of cyclic monoterpene inhibition of hepatic 3-hydroxy-3methylglutaryl coenzyme-A reductase in vivo in the rat. $J$ Biol Chem 257, 2294-2299.

5. Vonbergmann K, Beck A, Engel C, et al. (1987) Administration of a terpene mixture inhibits cholesterol nucleation in bile from patients with cholesterol gallstones. Klin Wochenschr 65, $458-462$.

6. Jung UJ, Lee MK, Park YB, et al. (2006) Effect of citrus flavonoids on lipid metabolism and glucose-regulating enzyme mRNA levels in type-2 diabetic mice. Int $J$ Biochem Cell B 38, 1134-1145.

7. Park SA, Choi MS, Kim MJ, et al. (2006) Hypoglycemic and hypolipidemic action of Du-zhong (Eucommia ulmoides Oliver) leaves water extract in C57BL/KsJ- $d b / d b$ mice. $J$ Ethnopharmacol 107, 412-417.

8. Kietzmann T \& Ganjam GK (2005) Glucokinase: old enzyme, new target. Expert Opin Ther Patents 15, 705-713.

9. Hanson RW \& Patel YM (1993) Phosphoenolpyruvate carboxykinase (Gtp) - the gene and the enzyme. Adv Enzymol Relat Areas Mol Biol 69, 203-281.

10. Nordlie RC, Bode AM \& Foster JD (1993) Recent advances in hepatic glucose 6-phosphatase regulation and function. Proc Soc Exp Biol Med 203, 274-285.

11. Pilkis SJ \& Granner DK (1992) Molecular physiology of the regulation of hepatic gluconeogenesis and glycolysis. Аnnu Rev Physiol 54, 885-909.

12. Bogan JS, Mckee AE \& Lodish HF (2001) Insulin-responsive compartments containing GLUT4 in 3T3-L1 and CHO cells: regulation by amino acid concentrations. Mol Cell Biol 21, $4785-4806$.

13. Suzuki STN, Zhao BP \& Yang JZ (2008) Enhanced muscle by myostatin propeptide increases adipose tissue adiponectin, PPAR- $\alpha$, and PPAR- $\gamma$ expressions. Biochem Biophys Res Commun 369, 767-773.

14. Chung MJ, Kang AY, Park SO, et al. (2007) The effect of essential oils of dietary wormwood (Artemisia princeps), with and without added vitamin E, on oxidative stress and some genes involved in cholesterol metabolism. Food Chem Toxicol 45, 1400-1409.

15. Bisset NG \& Wichtl M (1994) Herbal Drugs. Stuttgart: Medpharm GmbH Scientific Publishers.

16. Lamaison JL \& Carnat A (1990) Levels of principal flavonoids in flowers and leaves of Crataegus-Monogyna Jacq and Crataegus-Laevigata (Poiret) Dc (Rosaceae). Pharm Acta Helv 65, $315-320$.

17. Agata I, Kusakabe H, Hatano T, et al. (1993) Melitric acid-A and acid-B, new trimeric caffeic acid-derivatives from Melissa officinalis. Chem Pharm Bull 41, 1608-1611.
18. Mulkens A \& Kapetanidis I (1987) Flavonoids of Melissa officinalis L. leaves (Lamiaceae). Pharm Acta Helv 62, 19-22.

19. Carnat AP, Fraisse D \& Lamaison JL (1998) The aromatic and polyphenolic composition of lemon balm (Melissa officinalis L. subsp. officinalis) tea. Pharm Acta Helv 72, 301-305.

20. Berrougui H, Cloutier M, Isabelle M, et al. (2006) Phenolicextract from argan oil (Argania spinosa L.) inhibits human low-density lipoprotein (LDL) oxidation and enhances cholesterol efflux from human THP-1 macrophages. Atherosclerosis 184, 389-396.

21. de Sousa AC, Alviano DS, Blank AF, et al. (2004) Melissa officinalis L. essential oil: antitumoral and antioxidant activities. J Pharm Pharmacol 56, 677-681.

22. Mimica-Dukic N, Bozin B, Sokovic M, et al. (2004) Antimicrobial and antioxidant activities of Melissa officinalis L. (Lamiaceae) essential oil. J Agric Food Chem 52, 2485-2489.

23. Singh N \& Rajini PS (2004) Free radical scavenging activity of an aqueous extract of potato peel. Food Chem 85, $611-616$

24. Im SS, Kang SY, Kim SY, et al. (2005) Glucose-stimulated upregulation of GLUT2 gene is mediated by sterol response element-binding protein-1c in the hepatocytes. Diabetes $\mathbf{5 4}$ 1684-1691.

25. Kamijo Y, Hora K, Nakajima T, et al. (2007) Peroxisome proliferator-activated receptor $\alpha$ protects against glomerulonephritis induced by long-term exposure to the plasticizer di-(2-ethylhexyl)phthalate. J Am Soc Nephrol 18, 176-188.

26. Wood IS, Hunter L \& Trayhurn P (2003) Expression of class III facilitative glucose transporter genes (GLUT-10 and GLUT-12) in mouse and human adipose tissues. Biochem Biophys Res Commun 308, 43-49.

27. Repa JJ, Turley SD, Quan G, et al. (2005) Delineation of molecular changes in intrahepatic cholesterol metabolism resulting from diminished cholesterol absorption. J Lipid Res 46, 779-789.

28. Bashan N, Kovsan J, Kachko I, et al. (2009) Positive and negative regulation of insulin signaling by reactive oxygen and nitrogen species. Physiol Rev 89, 27-71.

29. Brownlee M (2001) Biochemistry and molecular cell biology of diabetic complications. Nature 414, 813-820.

30. Ceriello A \& Testa R (2009) Antioxidant anti-inflammatory treatment in type 2 diabetes. Diabetes Care 32, S232-S236.

31. Decaux JF, Marcillat O, Pichard AL, et al. (1991) Glucosedependent and glucose-independent effect of insulin on gene expression. J Biol Chem 266, 3432-3438.

32. Fukuda H, Katsurada A \& Iritani N (1992) Nutritional and hormonal regulation of messenger RNA levels of lipogenic enzymes in primary cultures of rat hepatocytes. $J$ Biochem (Tokyo) 111, 25-30.

33. Brocklehurst KJ, Payne VA, Davies RA, et al. (2004) Stimulation of hepatocyte glucose metabolism by novel small molecule glucokinase activators. Diabetes $\mathbf{5 3}, 535-541$.

34. Dentin R, Pegorier JP, Benhamed F, et al. (2004) Hepatic glucokinase is required for the synergistic action of ChREBP and SREBP-1c on glycolytic and lipogenic gene expression. J Biol Chem 279, 20314-20326.

35. Doiron B, Cuif MH, Kahn A, et al. (1994) Respective roles of glucose, fructose, and insulin in the regulation of the liverspecific pyruvate-kinase gene promoter. J Biol Chem 269, 10213-10216.

36. Ferre T, Riu E, Bosch F, et al. (1996) Evidence from transgenic mice that glucokinase is rate limiting for glucose utilization in the liver. FASEB $J \mathbf{1 0}, 1213-1218$.

37. Argaud D, Zhang Q, Pan WS, et al. (1996) Regulation of rat liver glucose-6-phosphatase gene expression in different nutritional and hormonal states: gene structure and $5^{\prime}$-flanking sequence. Diabetes 45, 1563-1571. 
38. Munoz MC, Barbera A, Dominguez J, et al. (2001) Effects of tungstate, a new potential oral antidiabetic agent, in Zucker diabetic fatty rats. Diabetes 50, 131-138.

39. Reaven GM (1997) Role of insulin resistance in human disease - syndrome X revisited. Atherosclerosis 134, 3.

40. Davies GF, Khandelwal RL, Wu LY, et al. (2001) Inhibition of phosphoenolpyruvate carboxykinase (PEPCK) gene expression by troglitazone: a peroxisome proliferator-activated receptor- $\gamma$ (PPAR $\gamma$ )-independent, antioxidant-related mechanism. Biochem Pharmacol 62, 1071-1079.

41. Foretz M, Guichard C, Ferre P, et al. (1999) Sterol regulatory element binding protein-1c is a major mediator of insulin action on the hepatic expression of glucokinase and lipogenesis-related genes. Proc Natl Acad Sci U S A 96, 12737-12742.
42. Kim SY, Kim HI, Kim TH, et al. (2004) SREBP-1c mediates the insulin-dependent hepatic glucokinase expression. $J$ Biol Chem 279, 30823-30829.

43. Gregori C, Guillet-Deniau I, Girard J, et al. (2006) Insulin regulation of glucokinase gene expression: evidence against a role for sterol regulatory element binding protein 1 in primary hepatocytes. FEBS Lett 580, 410-414.

44. Kim H \& Ahn Y (2004) Role of peroxisome proliferator activated receptor- $\gamma$ in the glucose-sensing apparatus of liver and $\beta$-cells. Diabetes 53, S60-S65.

45. Kramer D, Shapiro R, Adler A, et al. (2001) Insulin-sensitizing effect of rosiglitazone (BRL-49653) by regulation of glucose transporters in muscle and fat of Zucker rats. Metabolism 50, $1294-1300$ 